\title{
Experiencing Disability in the School Context: Voices of Young People Diagnosed With ADHD in Spain
}

\author{
Paulo Padilla-Petry ${ }^{1}$, Carla Sòria-Albert ${ }^{1} \&$ Jennifer A. Vadeboncoeur ${ }^{2}$ \\ ${ }^{1}$ Department of Methods of Research and Diagnosis in Education (MIDE), Faculty of Education, University of \\ Barcelona (UB), Barcelona, Spain \\ ${ }^{2}$ Department of Educational and Counselling Psychology, and Special Education (ECPS), The University of \\ British Columbia (UBC), The University of British Columbia, Vancouver, Canada \\ Correspondence: Paulo Padilla-Petry, Faculty of Education, University of Barcelona, Passeig de la Vall d'Hebron, \\ 171, Barcelona, 08035, Spain. Tel: 349-3403-5220. E-mail: ppadillapetry@ub.edu
}

Received: March 20, 2018

Accepted: April 21, $2018 \quad$ Online Published: July 28, 2018

doi:10.5539/ies.v11n8p79

URL: https://doi.org/10.5539/ies.v11n8p79

\begin{abstract}
Researchers have begun to inquire into the experiences of young people with ADHD, including how they define ADHD and how a diagnosis of ADHD affects them. ADHD is considered a neurodevelopmental disorder and diagnosis is frequently requested by school professionals. The purpose of this qualitative study was to examine the experiences of young people in Spain who are diagnosed with ADHD through student voice research. Using semi-structured interviews, we found that while the participants tended to reproduce the conventional psychiatric discourse on ADHD, they also produced their own explanation of ADHD and of the effects of being labelled with ADHD on their lives in school. Our results highlight both the school's role in advocating for a diagnosis of ADHD and the lack of an adequate instructional response for students once they have been diagnosed.
\end{abstract}

Keywords: ADHD, coping with ADHD, medicalization of childhood, social construction of ADHD, schooling, youth voices

\section{Introduction}

For over a decade, Attention-Deficit/Hyperactivity Disorder (ADHD) has been a topic of debate across disciplines (e.g., Pajo \& Cohen, 2013; Visser \& Jehan, 2009). This debate is framed by both 1) media accounts of the presence of mental illness in children and the necessity of expert medical intervention (Lloyd \& Norris, 1999; Singh, 2002) and 2) criticism for the overdiagnosis of ADHD and the pathologization of childhood (Malacrida, 2004). Although contextualized within various disciplines (biomedical, psychological and sociological), ADHD is currently presented as having a biological cause; a perspective considered indisputable by many researchers (see Akinbami et al., 2011; Houghton, 2006; Valera et al., 2007). One outcome of seeing ADHD exclusively through a biomedical lens (Visser \& Jehan, 2009) is that it contributes to removing the blame for ADHD from a person, most often the child or the parent (Lakoff, 2000). In maintaining the dichotomy between the individual and the social context, however, and further narrowing the cause to a biological flaw in an individual's brain, the remedy for ADHD becomes medical treatment, and opportunities for better understanding the effects of social contexts, like schools, on ADHD are reduced (Singh, 2004). In addition, and our principal concern, opportunities for investigating the relationship between individual and social context are lost.

Alongside of the concern surrounding ADHD, there is limited research on the social construction of ADHD, regarding what children and young people diagnosed with ADHD think and feel about their lives and diagnoses (Gibbs, Mercer, \& Carrington, 2016). In addition, there is a growing interest in the conduct of research into students' perspectives and experiences as one avenue for eliciting students' voices (see for review, Gonzalez, Hernandez-Saca, \& Artiles, 2016). Drawing from human rights literature, documenting the voices of young people with and without disabilities has been acknowledged as important in a number of international studies (e.g., Jacquez, Vaughn, \& Wagner, 2013; Schneider, 2015). While noting the ambiguity in youth voice research (Komulainen, 2007), our goal was to inquire into and gather the experiences of young people diagnosed with ADHD in Spain. Divided into five sections, we 1) describe ADHD in the school context; 2) examine the literature on youth voice research with children and youth with disabilities; 3 ) describe our methods; 4) present findings and; 5) provide a discussion and conclusion. 


\section{ADHD and the School Context}

Research into the association between ADHD and academic difficulties is conducted in various ways. Many studies have examined the relationship between ADHD, executive functions and specific learning disorders (e.g., DuPaul, Gormley, \& Laracy, 2013; Katz et al., 2011; Mattison \& Mayes, 2012; Weiler et al., 2002). According to DuPaul et al. (2013), the comorbidity between ADHD and learning disorders may vary greatly from one study to another and it is relatively high $(31 \%$ to $45 \%)$. Other studies have tried to discriminate between ADHD/I (Inattentive type) and ADHD/C (Combined type) either by testing Barkley's executive functions hypothesis (e.g., Biederman et al., 2004; Geurts et al., 2005) or by relating ADHD/I with Sluggish Cognitive Tempo (SCT) characteristics (e.g., Capdevila-Brophy et al., 2014; Harrington \& Waldman, 2010; Marshall et al., 2014; Milich, Balentine, \& Lynam, 2001) or other variables (e.g. Grizenko, Paci, \& Joober, 2010).

Although studies confirm the association between ADHD and different degrees of learning difficulties, they also expose the discrepancies in the possible causes and manifestations of different learning problems related to ADHD. For example, some research challenged the notion that ADHD/C and ADHD/I are the same disorder (e.g., Capdevila-Brophy et al., 2014; Grizenko et al., 2010; Milich et al., 2001), while Weiler et al. (2002) suggested that ADHD/I may not be a variant of ADHD, but rather a learning disability. Authors like Grizenko et al. (2010) and Marshall et al. (2014) point out the differences between the disruptiveness of ADHD/C and the social withdrawal of ADHD/I.

Some authors question the school's attitude towards ADHD (Bailey, 2010; Graham, 2007). Bell et al. (2010) studied the impact of teacher credentials on the perception of stigma associated with students with ADHD. They found that the amount of years of teaching experience did not seem to make any difference in the perception of stigma. Teachers with special education certification, however, were more aware of the stigma encountered by students with ADHD. Using mixed methods, Liang and Gao (2016) studied pre-service and in-service secondary school teachers' knowledge and attitudes towards students with ADHD finding no significant differences between groups; all participants considered having students with ADHD in class a burden.

Yet, teachers have an important role in recognizing and referring children with ADHD because they spend a great amount of time with children with and without ADHD (Moldavsky et al., 2013). In a systematic review of qualitative research that explored the relationship between teachers and parents of pupils diagnosed with ADHD, Gwernan-Jones et al. (2015) found that teachers often have the role of knowledgeable professionals while parents must be the passive receptors of expert advice. Since many teachers think that poor parenting may cause ADHD, 'parent-teacher conflict may be aggravated because parents felt criticized and insulted by teachers who seemed to blame them for their child's difficulties' (Gwernan-Jones et al., 2015, p. 295).

Conventional pedagogical approaches rely heavily on the role of teacher as the source of knowledge to be transmitted to the students who are expected to present a range of behaviours that are precisely the opposite of the ADHD diagnostic criteria (Prosser, 2008). A mismatch between these approaches and developing ways of learning could be wrongly interpreted as ADHD, which tends to favour education policies that are reductionist, medicalized, and deficit-laden and avoid scrutiny of the school environment (Prosser, 2008). The deficit thinking that grounds this perspective of the difference between expected and actual behaviours in schools is linked to and reinforced by biases around ethnicity, social class, and gender (Croc, 2017; Valencia, 2010). While special education, in general, and inclusive education, more specifically, have become expectations in many schools, current research highlights the ongoing struggle for equitable educational experiences and outcomes across cultures and contexts (e.g., Artiles, Kozleski, \& Waitoller, 2011; Sullivan \& Artiles, 2011).

Research in Canada and the United Kingdom (UK) found that some parents searched for an ADHD diagnosis after being pushed by school personnel (Malacrida, 2004). In fact, the rate of ADHD diagnoses tends to drop after the age of compulsory schooling and parents have noted that it is not necessary for children to take their medication during weekends or holidays (Martins et al., 2004). In a sense then, for some children, ADHD may be considered a school disability, one that is inherently related to and a function of formal educational contexts and one that disappears or is not disabling in other contexts. This raises questions about the potential of over-diagnosis, as alluded to earlier, and contradicts the definition of ADHD as a disability in more than one setting (APA, 2013). Changes in schooling demands such as increased emphasis on academic learning and seatwork and/or 'crowding' the curriculum are not considered as possible causal factors (Graham, 2008). Indeed, there are few scholars who study the possibility of schooling itself as a factor contributing to ADHD (see, however, calls for this kind of research by Bailey, 2010; Graham, 2007).

\section{Listening to and Learning from Youth Diagnosed with ADHD}

Research has been conducted into both parents' beliefs and parents' and adolescents' views on ADHD. For 
example, studies examined parents' beliefs about ADHD, their decision-making and reasoning processes when seeking help and their willingness to accept medication treatment for ADHD (e.g., Cormier, 2012; Maniadaki et al., 2006; Sciutto, 2015). Further, Bussing and colleagues conducted research into parent and adolescent views on ADHD using standardized measures of different variables related to ADHD such as: the parents' and the youth's sources of information on ADHD, the self-esteem of children in special education programs at high risk for ADHD, adolescent and parent perceived clinical need, knowledge about ADHD or willingness to use ADHD interventions (Bussing, Koro-Ljungberg, Noguchi, Mason, Mayerson, \& Garvan, 2012; Bussing, Zima, Mason, Meyer, White, \& Garvan, 2012; Bussing, Zima, Mason, Porter, \& Garvan, 2011; Bussing, Zima, \& Perwien, 2000).

In research on youths' perspectives, children and young people show independent decision-making when they talk about themselves and their diagnoses (Harwood, 2009; Singh, 2013a). Rejecting approaches that position the child as a victim and the adult (or the world of adults) as an offender who acts without concern for the child, Singh $(2010,2011,2012,2013 b)$ examined children's and young people's perspectives on different aspects related to ADHD, such as the relation between medication and moral agency or their descriptions of the brain, the self and behaviour. Her interest was, in part, to better understand how young people explain their behaviour and whether their actions are seen as caused by an external force, an uncontrollable brain, or the medication. Singh (2013a) found that children articulated a dynamic model of negotiations between the self and the brain in which the power to control their behaviour was constantly shifting.

Research has been conducted in several countries to investigate the perspectives of students regarding ADHD. In Australia, examining teenage students' perceptions of ADHD, pedagogy and school response, Prosser (2006) noted that the students felt the teachers treated them mainly for their behaviour, rather than for their ADHD label; medication was mainly used to comply with the expectations of schools, and; ADHD made a difference only at school. He concluded both that schools do not understand children and youth with ADHD and that children with ADHD do not understand the expectations of schoolwork. The necessity of appropriate teacher support has been emphasized in other studies (e.g., Gibbs et al., 2016). In Israel, research on the perspectives of adolescents with normal intelligence and both ADHD and Learning Disabilities (LD) highlighted the participants concerns with how they were treated by teachers: $17.2 \%$ said that the teachers should treat them with understanding and without criticism, angry or pity (Brook \& Boaz, 2005).

In Spain, like in most countries, the research on ADHD is dominated by the current hegemonic psychiatric view of $\mathrm{ADHD}$ as a disorder, caused by biological factors, related to poor academic results and problematic behaviour in school. Cross-cultural studies have not found any particular difference related to ADHD in Spain (Bauermeister et al., 2010; Hodgkins et al., 2013). Quantitative research exists, similar to Bussing's and Liang and Gao's studies, comparing variables such as the teacher's knowledge about ADHD or the parents and young people's perceptions of ADHD and family contexts (Fernández, Minguez, \& Casas, 2007; Ramón \& Sánchez, 2014). Although there are critical perspectives on ADHD in Spain, there does not appear to be qualitative research inquiring into the experience of young people diagnosed with ADHD.

Given the critique of youth voice research, we sought to provide an opportunity for young people to express their views of experiences in and out of school without taking a paternalistic position (Dunne \& Moore, 2011; Komulainen, 2007). Equally, like Singh (2013b), we were not looking for victims of ADHD's diagnoses, but were interested in hearing the participants' perspectives on their experience of being diagnosed with ADHD.

\section{Methods}

\subsection{Research Design}

The purpose of this qualitative research was to explore how young people diagnosed with ADHD/C defined and experienced ADHD, as well as the extent to which their responses were framed by a discourse of medicalization. Our investigation focused on participants' definitions and experiences, as well as how their diagnosis influenced their relationships in and out school. We were interested in investigating the meaning of ADHD and its symptomatic behaviours in life contexts (Dunne \& Moore, 2011; Singh, 2011). We considered the participants to be in the best position to talk about their experiences in a meaningful way; our role was to listen and learn (Hadfield \& Haw, 2001). We were also aware of the risk of speaking on behalf of young people with ADHD (see Fielding, 2004). Although interview questions inquired into the experience of ADHD in multiple contexts, students overwhelmingly spoke about ADHD in the school context.

\subsection{Participants}

Inclusion criteria included young people between the ages of 11 and 18 who had experienced difficulties in school 
and then followed up with a doctor or school psychologist to confirm their diagnosis. Participants received a document explaining the purposes and methods of the research; following ethical clearance procedures, this was signed by their parents or legal guardians for consent. The participants did not receive compensation for their participation in the research. For nine participants, the concern about having ADHD began with a teacher in relation to their behaviour in school; one participant asked to be tested after experiencing problems in school. The participants included six boys and four girls diagnosed with $\mathrm{ADHD} / \mathrm{C}$, recruited through chain referral sampling (Penrod et al., 2003), from three different cities in Spain who attended four different secondary schools. The first participants were referred by their psychologist and teachers. Two potential participants were excluded because they postponed the first interview multiple times.

Table 1. Participant information

\begin{tabular}{|c|c|c|c|}
\hline Pseudonym, age & Age at diagnosis & Diagnosed by & Medication \\
\hline Fernando, 11 & Unknown, already 11 & School psychologist & No, Valerian root. \\
\hline Carles, 14 & At 8 & School psychologist + external clinical psychologist & Yes \\
\hline Oriol, 15 & At 9 & School psychologist + external physician + external clinical psychologist & Yes \\
\hline Josep, 15 & At 11 & School psychologist + external clinical psychologist & Yes \\
\hline Diego, 16 & At 10 & School psychologist + external clinical psychologist & Yes \\
\hline Pablo, 16 & At 10 & School psychologist + external clinical psychologist & Yes \\
\hline Paula, 13 & Unknown, already 13 & School psychologist & No \\
\hline Laura, 17 & At 17 & School psychologist + external psychiatrist & Yes \\
\hline Nuria, 17 & At 13 & 2 external psychologists & No \\
\hline Carla, 18 & At 14 & School psychologist + external clinical psychologist & No \\
\hline
\end{tabular}

\subsection{Data Collection}

Since most of the recruited participants were not available for an in-depth interview, the data was collected through two semi-structured active interviews. First, ten participants completed a general interview ( \pm 20 minutes). Then, the four respondents who agreed to a second and in-depth interview ( \pm 40 minutes) went through it. Following Holstein and Gubrium (1997), these interviews were 'active': interviewing is a social interaction between the researcher, the second author, and the participants, thus, transcripts reflect a process of joint meaning making. The interview itself was a transformational encounter and the participants were 'always becoming in the exchange with the researcher and the research' (Davies \& Davies, 2007, p. 1142). Given ethical clearance, the interviews were conducted in environments that were well known: schools (6), recreational areas (2), and medical office meeting rooms (2).

Interviews were conducted in Catalan, the language of the participants, and audiotaped. Following demographic questions, the first interview included questions regarding the definition of ADHD and its impact on their lives, such as:

1) How do you explain ADHD to a boy or a girl, what is ADHD?

2) How do you know that?

3) How does ADHD affect you?

4) How would you be without ADHD?

5) What do you do when something does not go well?

The second interview focused on the participants' experiences with ADHD and included questions such as:

1) Prior to receiving the ADHD diagnosis, what caused it?

2) How long since you were first diagnosed and by whom?

3) What changed with the diagnosis?

4) Do you take any medication or go through some kind of psychotherapy?

5) What do you think about the treatment you are receiving? Do you like it? Would you change anything?

6) Do you think that ADHD has had any influence on your relationships? Could you give me an example?

7) Do you think that people treat you differently if they know you have ADHD? What if they do not know? Could you give me an example? 
8) What advice would you give to another boy or girl that has just been diagnosed with ADHD?

9) How do you see the future? Do you think that having ADHD will affect you in the future?

\subsection{Data Analysis}

After transcribing the interviews, the data from both interviews were thematically analysed through a six step process of coding and constructing categories from patterns in the responses both inductively and deductively (Braun \& Clarke, 2006). Thus, some categories such as 'the definition of ADHD' and 'the source of the information on ADHD' were related to questions and others like 'life without ADHD,' 'self-control strategies,' or 'how ADHD is a part of my personality' were drawn from across the interview responses. In this article, all names used are pseudonyms and segments of the transcripts have been translated from Catalan to English.

\section{Results}

To present our findings, we grouped the categories into three main themes, including defining ADHD as a disability; diagnosing ADHD and relational effects and; coping with ADHD.

\subsection{Defining ADHD as a Disability}

Participants reported that most of their information about ADHD originated from explanations of private psychiatrists and psychologists or school psychologists; this was later complemented by searching the Internet and books. Although the participants' definitions of ADHD incorporated some of the lexical items of the dominant psychological discourse on ADHD, they were able to explain their diagnosis in what seemed to be their own words and to add information that was clearly drawn from their own experiences predominantly in schools.

The majority of the participants used medical words to define ADHD. Nine of ten participants defined ADHD as a 'sickness,' a 'disorder,' or a 'trouble' that affected them whenever they tried to concentrate on a task or to control their impulses and nervous state. All the participants' definitions were related to the three key characteristics of ADHD: excess of activity and impulsivity and/or lack of attention. One girl said that 'ADHD is a disorder that troubles one's attention towards something such as listening to someone or memorising something (...) the excess of activity makes it complicated to control one's nervous state and makes one act impulsively' (Carla, 18 yrs old). One boy defined ADHD as a 'mental disability that makes you restless, does not let you pay attention, distracts you and makes you bother other people' (Pablo, 16 yrs old). The participants characterised themselves as 'nervous people' and some of them also as impulsive people and their definitions and examples reflected experiences in the school context.

The participants associated ADHD with both 'bad behaviour' and poor academic results because it 'makes you nervous and does not let you stop' (Oriol, 15 yrs old). Although the participants queried how the ADHD label could be synonymous with bad behaviour for the teachers, the participants acknowledged they bothered other people, not only teachers. ADHD was said to affect their 'capacity to be quiet' or to generate 'a build-up of energy that does not let you stop' (Nuria, 17 yrs old). The restlessness they felt when they needed to be quiet and focused caused them distress. It could be mitigated through movement, but it also worsened given the adults' interventions. Diego (16 yrs old) reported that he became more agitated when the adults constantly called his attention to his failure to concentrate on one task.

In the experiences of the participants, ADHD interfered with the time dedicated to study. Grades and overall results did not reflect their efforts at studying, what they had learned, and their knowledge. In addition, the boredom that required movement in order to stay calm was considered disruptive in the school context. 'Boredom' was especially relevant since it was often related to the lack of motivation felt by the participants, but never to the school itself. Our results confirm findings by Gibbs et al. (2016): although some school subjects were thought to be more interesting than others, and different participants said that they attended only to those, ADHD explained the lack of concentration and the need to move and talk whenever the participants got bored with their subjects. Overall, they thought that without ADHD they would listen more to other people, control themselves better, be calmer and less impulsive, and not lose concentration as frequently. They also felt they would have better grades because they would be able to study longer. Josep (15 yrs old) noted that without ADHD he would be smarter; ADHD made him feel dumb and inferior to other people.

Two participants, however, had a different perspective: 'I cannot imagine myself without ADHD, (...) I have learned to accept myself as I am and take advantage of all this energy I have to do a thousand things' (Nuria, 17 yrs old). Nuria argued that ADHD gave her mental agility and, because of that, she would rather answer oral tests instead of written ones. Another participant argued that, although without ADHD she would be less clueless, she liked herself as she was (Carla, 18 yrs old). 


\subsection{Diagnosing a Disability and the Relational Effects}

Nine of the participants were diagnosed with ADHD because their teachers complained to parents about their behaviour and advised getting assessed: 'My teachers told my parents that my lack of attention and my behaviour problems happened too often. We went to the paediatrician and he sent us to a psychologist' (Oriol, 15 yrs old). The participants' parents searched for a diagnosis from a mental health professional. Some parents had to talk with more than one psychologist or psychiatrist because the first would not confirm the ADHD diagnosis suspected by the school professionals. For these participants, parents seemed to value the teachers' perspectives as school insiders, over the independent perspectives of psychologists outside of schools.

According to the participants, the school's pathologization of their conduct was based less on ADHD symptoms, and more on bad behaviour. Some explained the school's attitude as an injustice with an angry tone. The feeling of being judged and labelled by school was present in the participants' comments. Although they did not challenge their diagnosis, they also did not feel supported by their schools' staff and often felt unfairly blamed and punished. The single participant whose diagnosis did not come after a request for assessment by the school was a girl who actively looked for an ADHD diagnosis after knowing about her friend's ADHD and feeling strongly identified with him (Nuria, 17 yrs old). She stated that the ADHD diagnosis helped her understand a number of things about her childhood.

Considering the stigma related to mental health difficulties (Bellanca \& Pote, 2013), the participants told us about their parents', teachers' and friends' reactions. Pablo (16 yrs old) stated that his parents began to treat him differently: they started explaining and forgiving everything he did because of ADHD, which was something that pleased him. Another boy (Carles, 14 yrs old) described his mother's attitude change and how she started to blame ADHD for everything he did, although his father did not share the same attitude. Diego (16 yrs old) noted that the ADHD diagnosis had not changed his relationship with other people and that its effects were limited to studying, although he thought that his mother had started to better understand his behaviour.

Surprisingly, the diagnosis of ADHD did not seem to change teachers' behaviours. From the perspective of the participants, their teachers' attitudes did not change with a confirmation of the ADHD diagnosis by a mental health professional. The teachers continued to punish them just like before. The perceived lack of teacher support was a common complaint of the participants. There was also a perception that the ADHD label had actually made the participants the preferred targets of the teachers' complaints.

The participants acknowledged their difficulties in initiating and sustaining friendships (Gibbs et al., 2016), but felt that the effects of the ADHD diagnosis on their friends were definitely unpleasant. Pablo (16 yrs old) noted that, besides losing friends because of his impulsiveness, when he told his childhood friends about his diagnosis, they did not understand it and laughed at him. He decided to avoid the friends that knew about his diagnosis and not tell anyone else. He wanted to be seen as normal and treated as an equal. Another boy and one of the girls also complained about their friends' lack of understanding. Nuria (17 yrs old) described making other people nervous; this led to a bad first impression. Nevertheless, she explained that she tried to be patient with herself and often asked for a second opportunity by telling people that underneath her excess of movement there was a person with other qualities and defects.

\subsection{Coping with $A D H D$}

The participants shared a number of strategies for coping with ADHD. When they felt frustrated for not being able to do a task, it helped them to run, walk, or do some sport. Fernando (11 yrs old) noted with a sad tone in his voice: 'when I played soccer, it was very good for discharging all the energy, but now I do not play it anymore because my coach told me that I was too nervous.' Singh et al. (2010) stated that young people with ADHD find that physical activity is helpful to them and our participants' interest in sports confirmed this. According to the participants, sports and physical activity provided an opportunity for 'discharging the energy that builds up.' Another clear advantage of practising sports was the increased perception of normality. Of course, as Fernando's (11 yrs old) experience reflects, children with ADHD have trouble even in sports if their behaviour does not fit the coach's expectations.

Along with sports or physical activity, some participants spoke to other people or asked for help when they were nervous. Another strategy was to write down what they felt whenever they were anxious or nervous. Josep (15 yrs old) said that his psychologist had told him that writing might help and, since he considered himself shy, keeping a journal seemed like a worthwhile strategy. Psychologists also taught the participants strategies such as relaxation and breathing techniques. Despite the strategies and the medication, participants described continued experiences in which they lost control, got mad, or became nervous, which later made them feel sad, helpless, and afraid of the opinions of others. 
Three of the four participants who completed the in-depth interview were taking stimulant medication for ADHD and they shared a similar opinion about it. Pablo (16) noted that, although he did not like it, he needed it to control himself and not bother other people. He also participated in and was learning from psychotherapy how to control his impulses and restlessness and was enjoying it. Carles (14 yrs old) complained about having to take the medication every day, but thought that it worked 'pretty well.' Initially, he was only participating in psychotherapy, but his mother looked for another professional, a psychiatrist or physician, who would give him medication to help him get 'better faster.' Diego (16 yrs old) concurred with the other two participants in that taking the medication every day was unpleasant, but necessary. Interestingly, he complained about feeling too relaxed and said that 'sometimes I feel that I am not myself, that I am sleepy, dazed' (Diego, 16 yrs old). He suggested, with irony, that his parents should have found a similar medication to calm them down.

\section{Discussion and Conclusions}

ADHD may be seen as a set of de-valued behaviours that differs in different countries (Singh, 2011). For example, lack of self-control in response to aggressive situations is emphasized in the United Kingdom and poor school performance is emphasized in the United States. However, prior to this study there did not appear to be any qualitative research inquiring into the experiences of young people diagnosed with ADHD in Spain. Our participants described their behaviour in ways consistent with both sets of de-valued behaviours. Although our interview questions were more general, the participants' descriptions revolved around their lives in schools. The two participants who presented ADHD as a part of them and defended its positive aspects seemed to use the diagnosis to better understand themselves. Although psychiatric diagnoses may allow students, parents, and teachers to make sense of some behaviours by categorizing them as a manifestation of a particular disability, in the case of ADHD, the extent to which their behaviour became a disability as a function of the context of schooling was not questioned (Graham, 2008).

The ideological and scientific debates around ADHD 'often fall along contentious lines of antipathy or enthusiasm for the diagnosis' (Malacrida, 2004, p. 64). However, none of our participants questioned or tried to deny their diagnosis; one of them requested it. All participants repeated in some way the psychiatric discourse on ADHD, but, besides telling us about ADHD symptoms, they described their experiences, feelings, distress, and coping strategies for life in schools. They confirmed ADHD's main characteristics: lack of attention, impulsivity, and excess of movement. Yet, they also gave us their way of understanding the symptoms: as a build-up of energy or a nervous state; as something that makes you restless and move, makes you bother other people, makes all your academic efforts seem useless, and that does not let you concentrate or pay attention.

For eight participants, ADHD was described as an internal, brain based and uncontrollable condition that affected their relationships and school tasks and activities negatively. This condition remained unrelated to their subjectivity and personality, and was consistent with the linear causation proposed by current neuroscientific research (MacNaughton, 2004). While undesired behaviours were attributed to this particular condition, the social context of schooling - in particular, the tasks that may have generated or contributed to boredom and the adult requests that may have caused uneasiness - remained unquestioned. Moreover, the only participant that claimed ADHD was an important, positive, part of her personality did not question the situations that usually generated conflicts and were attributed to ADHD. All participants seemed convinced that ADHD was the sole cause of the academic and social problems they faced. This perspective was consistent with the biological conceptualization of ADHD as an objective condition that impairs a student's social and academic life, and is unrelated to social or contextual variables.

Participants confirmed both the learning difficulties associated with ADHD and the decisive role played by school personnel, rather than medical personnel, in motivating the diagnosis process and the medicalization of ADHD (Conrad, 1982, 1992). Similar with Malacrida's (2004) research in the UK and Canada, some families searched for a second opinion when the first doctor did not confirm the ADHD diagnosis suspected by educators in schools. More than confirming a diagnosis, however, the families needed a treatment that would repair the student and, thus, enable him or her to meet the school's requirements. Unfortunately, once the diagnosis was confirmed and the medication taken, the responsibility of both the school and parent was perceived to be fulfilled. It did not appear that educators made changes to classroom routines to provide students with differentiated curricula or accommodations to improve their learning conditions.

As our participants were diagnosed with $\mathrm{ADHD} / \mathrm{C}$, their differences were observable in the behaviours they manifested, rather than less easily visible, as, for example, for a young person with learning difficulties and/or ADHD/I. This may have contributed to the motivating concerns of school personnel, their treatment with medicine, and the medicalization of their experience. In general, the participants seemed tired of being seen as 
'sick people,' especially when they managed to do some things well. They realized that they bothered other people, and given that ADHD was explained to them to be a biological condition, there seemed to be an underlying question about the effects of ADHD on their capacity to act of their own volition (Singh, 2011). Although some may have enjoyed not being held responsible for their behaviour, they also wished to be accepted as normal people and they felt sad and worried about other people's opinions about them. The possible conflict between these opposing feelings was not explored in our research and remains a possible subject of further investigation.

Our research was an investigation of experiences of ADHD through youth voice research in the Spanish context, where almost all the research about ADHD confirms a hegemonic biological view. Our results are limited to the participants' experiences. It does seem clear that the young people who agreed to tell us about their lives with ADHD sometimes behaved in ways that concerned them and others and made them feel ashamed. Although their behaviours could not be always related to ADHD symptoms, they ended up being recognised by the participant and the adults around them as expressions of ADHD as a disabling condition. Medication, psychotherapy, self-control strategies, and other interventions were used by the participants to fit in at school. None of the participants expected teachers or schools to change for them, although they wished changes were possible and offered ideas for what teachers and schools might do to help them.

We wonder, however, what educators might do to transform schools into the inclusive settings they could be: schools where young people, like the participants of our research, could think of themselves as nervous people that may need to move more than others, without feeling a sense of exclusion and shame. Schools where differences are acknowledged, expected, and included, rather than assimilated, may both reduce the extent to which children and youth with ADHD are marginalized and form guiding principles for the educators in them.

\section{References}

Akinbami, L. J., Liu, X., Pastor, P. N., \& Reuben, C. A. (2011). Attention Deficit Hyperactivity Disorder among children aged 5-17 years in the United States, 1998-2009. National Center for Health Statistics Data Brief, $70,1-8$.

American Psychiatric Association. (2013). Diagnostic and statistical manual of mental disorders (5th ed.). Washington, DC: American Psychiatric Publishing. https://doi.org/10.1176/appi.books. 9780890425596

Artiles, A. J., Kozleski, E. B., \& Waitoller, F. R. (2011). Inclusive education: Examining equity on five continents. Cambridge, MA: Harvard Education Press.

Bailey, S. (2010). The DMS and the dangerous child. International Journal of Inclusive Education, 14(6), 581-592. https://doi.org/10.1080/13603110802527961

Bauermeister, J. J., Canino, G., Polanczyk, G., \& Rohde, L. A. (2010). ADHD across cultures: Is there evidence for a bidimensional organization of symptoms? Journal of Clinical Child \& Adolescent Psychology, 39(3), 362-372. https://doi.org/10.1080/15374411003691743

Bell, L., Long, S., Garvan, C., \& Bussing, R. (2011). The impact of teacher credentials on ADHD stigma perceptions. Psychology in the Schools, 48(2), 184-197.

Bellanca, F. F., \& Pote, H. (2013). Children's attitudes towards ADHD, depression and learning disabilities. Journal of Research in Special Educational Needs, 13(4), 234-241. https://doi.org/10.1111/j.1471-3802.2012.01263.x

Biederman, J., Monuteaux, M. C., Doyle, A. E., Seidman, L. J., Wilens, T. E., Ferrero, F., ... Faraone, S. V. (2004). Impact of executive functions deficits and Attention-Deficit/Hyperactivity Disorder (ADHD) on academic outcomes in children. Journal of Consulting and Clinical Psychology, 72(5), 757-766. https://doi.org/10.1037/0022-006X.72.5.757

Braun, V., \& Clarke, V. (2006). Using thematic analysis in psychology. Qualitative Research in Psychology, 3(2), 77-101. https://doi.org/10.1191/1478088706qp063oa

Brook, U., \& Boaz, M. (2005). Attention deficit and hyperactivity disorder (ADHD) and learning disabilities (LD): Adolescents perspective. Patient Education and Counseling, 58, 187-191. https://doi.org/10.1016/j.pec.2004.08.011

Bussing, R., Koro-Ljungberg, M., Noguchi, K., Mason, D., Mayerson, G., \& Garvan, C. (2012). Willingness to use ADHD treatments: A mixed methods study of perceptions by adolescents, parents, health professionals and teachers. Social Science and Medicine, 74(1), 92-100. https://doi.org/10.1016/j.socscimed.2011.10.009

Bussing, R., Zima, B. T., \& Perwien, A. R. (2000). Self-esteem in special education children with ADHD: 
Relationship to disorder characteristics and medication use. Journal of the American Academy of Child and Adolescent Psychiatry, 39(10), 1260-1269. https://doi.org/10.1097/00004583-200010000-00013

Bussing, R., Zima, B. T., Mason, D. M., Meyer, J. M., White, K., \& Garvan, C. W. (2012). ADHD knowledge, perceptions and information sources: Perspectives from a community sample of adolescents and their parents. Journal of Adolescent Health, 51(6), 593-600. https://doi.org/10.1016/j.jadohealth.2012.03.004

Bussing, R., Zima, B., Mason, D. M., Porter, P. C., \& Garvan, C. W. (2011). Receiving treatment for attention deficit/hyperactivity disorder: Do adolescents' perspectives matter? Journal of Adolescent Health, 49(1), 7-14. https://doi.org/10.1016/j.jadohealth.2010.08.014

Capdevila-Brophy, C., Artigas-Pallarés, J., Navarro-Pastor, J. B., García-Nonell, K., Rigau-Ratera, E., \& Obiols, J. E. (2014). ADHD predominantly inattentive subtype with sluggish cognitive tempo: A new clinical entity? Journal of Attention Disorders, 18(7), 607-616. https://doi.org/10.1177/1087054712445483

Conrad, P. (1982). Sobre la medicalización de la anormalidad y el control social [About medicalization of the abnormality and social control]. In D. Ingleby (Ed.), Psiquiatría crítica: La politica de la salud mental [Critical psychiatry: The politics of mental health] (pp. 129-154). Barcelona: Crítica-Grijalbo

Conrad, P. (1992). Medicalization and social control. Annual Review of Sociology, 18, 209-232. https://doi.org/10.1146/annurev.so.18.080192.001233

Cormier, E. (2012). How parents make decisions to use medication to treat their child's ADHD: A grounded theory study. Journal of the American Psychiatric Nurses Association, 18(6), 345-356. https://doi.org/10.1177/1078390312466918

Croc, N. (2017). Examining disparities in teacher perceptions of student disabilities. Teachers College Record, $119(7), 1-32$.

Davies, B., \& Davies, C. (2007). Having, and being had by, "experience": Or, "experience" in the social sciences after the discursive/ poststructuralist turn. Qualitative Inquiry, 13, 1139-1159. https://doi.org/10.1177/1077800407308228

Dunne, L., \& Moore, A. (2011). From boy to man: A personal story of ADHD. Emotional and Behavioural Difficulties, 16(4), 351-364. https://doi.org/10.1080/13632752.2011.616339

DuPaul, G. J., Gormley, M. J., \& Laracy, S. D. (2013). Comorbidity of LD and ADHD: Implications of DSM-5 for assessment and treatment. Journal of Learning Disabilities, 46(1), 43-51. https://doi.org/10.1177/0022219412464351

Fernández, S. J., Minguez, R. T., \& Casas, A. M. (2007). Teachers' knowledge, misconceptions, and lacks concerning Attention Deficit Hyperactivity Disorder. Psicothema, 19(4), 585-590.

Fielding, M. (2004). Transformative approaches to student voice: Theoretical underpinnings, recalcitrant realities. British Educational Research Journal, 30(2), 295-311. https://doi.org/10.1080/0141192042000195236

Geurts, H. M., Verté, S., Oosterlaan, J., Roeyers, H., \& Sergeant, J. A. (2005). ADHD subtypes: Do they differ in their executive functioning profile? Archives of Clinical Neuropsychology, 20, 457-477. https://doi.org/10.1016/j.acn.2004.11.001

Gibbs, K, Mercer, K. L., \& Carrington, S. (2016). The schooling experience of adolescent boys with AD/HD: An Australian case study. International Journal of Disability, Development and Education, 63(6), 608-622. https://doi.org/10.1080/1034912X.2016.1164302

Gonzalez, T. E., Hernandez-Saca, D. I., \& Artiles, A. J. (2016). In search of voice: Theory and methods in K-12 student voice research in the US, 1990-2010. Educational Review. https://doi.org/10.1080/00131911.2016.1231661

Graham, L. (2007). Out of sight, out of mind/out of mind, out of site: Schooling and attention deficit hyperactivity disorder. International Journal of Qualitative Studies in Education, 20(5), 585-602. https://doi.org/10.1080/09518390601176705

Graham, L. (2008). From ABCs to ADHD: The role of schooling in the construction of behaviour disorder and production of disorderly objects. International Journal of Inclusive Education, 12(1), 7-33. https://doi.org/10.1080/13603110701683311

Grizenko, N., Paci, M., \& Joober, R. (2010). Is the inattentive subtype of ADHD different from the Combined/Hyperactive subtype? Journal of Attention Disorders, 13(6), 649-657. 
https://doi.org/10.1177/1087054709347200

Gwernan-Jones, R., Moore, D. A., Garside, R., Richardson, M. Thompson-Coon, J., Rogers, M., ... Ford, T. (2015). ADHD, parent perspectives and parent-teacher relationships: grounds for conflict. British Journal of Special Education, 42(3), 279-300. https://doi.org/10.1111/1467-8578.12087

Hadfield, M., \& Haw, K. (2001). 'Voice', young people and action research. Educational Action Research, 9(3), 485-502. https://doi.org/10.1080/09650790100200165

Harrington, K. M., \& Waldman, I. D. (2010). Evaluating the utility of sluggish cognitive tempo in discriminating among DSM-IV ADHD subtypes. Journal of Abnormal Child Psychology, 38, 173-184. https://doi.org/10.1007/s10802-009-9355-8

Harwood, V. (2009). El diagnóstico de los niños y adolescentes 'problemáticos': Una crítica a los discursos sobre los trastornos de la conducta [Diagnosing disorderly children: A critique of behaviour disorder discourses]. Madrid: Morata.

Hodgkins, P., Setyawan, J., Mitra, D., Davis, K., Quintero, J., Fridman, M., Shaw, M., \& Harpin, V. (2013). Management of ADHD in children across Europe: Patient demographics, physician characteristics and treatment patterns. European Journal of Pediatrics, 172, 895-906. https://doi.org/10.1007/s00431-013-1969-8

Holstein, J. A., \& Gubrium, J. F. (1997). Active interviewing. In D. Silverman (Ed.), Qualitative research: Theory, method, and practice (pp. 113-129). Thousand Oaks, CA: Sage.

Houghton, S. (2006). Advances in ADHD research through the lifespan: Common themes and implications. International Journal of Disability, Development and Education, 53(2), 263-272. https://doi.org/10.1080/10349120600716208

Jacquez, F., Vaughn, L. M., \& Wagner, E. (2013). Youth as partners, participants, or passive recipients: A review of children and adolescents in community-based participatory research (CBPR). American Journal of Community Psychology, 51(1-2), 176-189. https://doi.org/10.1007/s10464-012-9533-7

Katz, L. J., Brown, F. C., Roth, R. M., \& Beers, S. R. (2011). Processing speed and working memory performance in those with both ADHD and a reading disorder compared with those with ADHD alone. Archives of Clinical Neuropsychology, 26, 425-433. https://doi.org/10.1093/arclin/acr026

Komulainen, S. (2007). The ambiguity of the child's 'voice' in social research. Childhood, 14(1), 11-28. https://doi.org/10.1177/0907568207068561

Lakoff, A. (2000). Adaptative will: The evolution of attention deficit disorder. Journal of the History of the Behavioral Sciences, $36(2), \quad 149-169$. https://doi.org/10.1002/(SICI)1520-6696(200021)36:2<149::AID-JHBS3>3.0.CO;2-9

Liang, L., \& Gao, X. (2016). Pre-service and in-service secondary school teachers' knowledge about Attention-deficit Hyperactivity Disorder (ADHD) and attitudes toward students with ADHD. International Journal of Disability, Development and Education, 63(3), 369-383. https://doi.org/10.1080/1034912X.2015.1123231

Lloyd, G., \& Norris, C. (1999). Including ADHD? Disability \& Society, 14(4), 505-517. https://doi.org/10.1080/09687599926091

MacNaughton, G. (2004). The politics of logic in early childhood research: A case of the brain, hard facts, trees and rhizomes. The Australian Educational Researcher, 31(3), 87-104. https://doi.org/10.1007/BF03249530

Malacrida, C. (2004). Medicalization, ambivalence and social control: Mothers' descriptions of educators and ADD/ADHD. Health: An Interdisciplinary Journal for the Social Study of Health, Illness and Medicine, 8(1), 61-80. https://doi.org/10.1177/1363459304038795

Maniadaki, K., Sonuga-Barke, E., Kakouros, E., \& Karaba, R. (2006). Parental beliefs about the nature of ADHD behaviours and their relationship to referral intentions in preschool children. Child, Care, Health and Development, 33(2), 188-195. https://doi.org/10.1111/j.1365-2214.2006.00642.x

Marshall, S. A., Evans, S. W., Eiraldi, R. B., Becker, S. P., \& Power, T. J. (2014). Social and academic impairment in youth with ADHD, predominately inattentive type and sluggish cognitive tempo. Journal of Abnormal Child Psychology, 42, 77-90. https://doi.org/10.1007/s10802-013-9758-4

Martins, S., Tramontina, S., Polanczyk, G., Eizirik, M., Swanson, J., \& Rohde, L. A. (2004). Weekend holidays 
during methylphenidate use in ADHD children: A randomized clinical trial. Journal of Child and Adolescent Psychopharmacology, 14(2), 195-204. https://doi.org/10.1089/1044546041649066

Mattison, R. E., \& Mayes, S. D. (2012). Relationships between learning disability, executive function, and psychopathology in children with ADHD. Journal of Attention Disorders, 16(2), 138-146. https://doi.org/10.1177/1087054710380188

Milich, R., Balentine, A. C., \& Lynam, D. R. (2001). ADHD combined type and ADHD predominantly inattentive type are distinct and unrelated disorders. Clinical Psychology: Science and Practice, 8(4), 463-488. https://doi.org/10.1093/clipsy.8.4.463

Moldavsky, M., Groenewald, C., Owen, V., \& Sayal, K. (2013). Teachers' recognition of children with ADHD: Role of subtype and gender. Child and Adolescent Mental Health, 18(1), 18-23. https://doi.org/10.1111/j.1475-3588.2012.00653.x

Pajo, B., \& Cohen, D. (2013). The problem with ADHD: Researchers' constructions and parents' accounts. International Journal of Early Childhood, 45, 11-33. https://doi.org/10.1007/s13158-012-0064-z

Penrod, J., Preston, D. B., Cain, R. E., \& Starks, M. T. (2003). A discussion of chain referral as a method of sampling hard-to-reach populations. Journal of Transcultural Nursing, 14(2), 100-107. https://doi.org/10.1177/1043659602250614

Prosser, B. (2006, November). Beyond deficit views: Engaging students with ADHD. Paper presented at the Australian Association for Research in Education Conference, Adelaide. Retrieved from http://www.researchgate.net/publication/265026621

Prosser, B. (2008). Beyond ADHD: A consideration of attention deficit hyperactivity disorder and pedagogy in Australian schools. International Journal of Inclusive Education, 12(1), 81-97. https://doi.org/10.1080/13603110701683147

Ramón, P. R., \& Sánchez, J. N. G. (2014). Family context of learning disabled or ADHD students, perceptions of parents and children. Estudios sobre Educación, 26, 149-173.

Schneider, C. (2015). Social participation of children and youth with disabilities in Canada, France, and Germany. International Journal of Inclusive Education, 19(10), 1068-1079. https://doi.org/10.1080/13603116.2015.1037867

Sciutto, M. J. (2015). ADHD knowledge, misconceptions, and treatment acceptability. Journal of Attention Disorders, 19(2), 91-98. https://doi.org/10.1177/1087054713493316

Singh, I, Kendall, T., Taylor, C., Mears, A., Hollis, C., Batty, M., \& Keenan, S. (2010). Young people's experience of ADHD and stimulant medication: A qualitative study for the NICE guideline. Child and Adolescent Mental Health, 15(4), 186-192. https://doi.org/10.1111/j.1475-3588.2010.00565.x

Singh, I. (2002). Bad boys, good mothers, and the 'miracle' of Ritalin. Science in Context, 15(4), 577-603. https://doi.org/10.1017/S0269889702000650

Singh, I. (2004). Doing their jobs: Mothering with Ritalin in a culture of mother-blame. Social Science and Medicine, 59, 1193-1205. https://doi.org/10.1016/j.socscimed.2004.01.011

Singh, I. (2011). A disorder of anger and aggression: Children's perspectives on attention deficit/hyperactivity disorder in the UK. Social Science and Medicine, 73, 889-896. https://doi.org/10.1016/j.socscimed.2011.03.049

Singh, I. (2012). Not robots: Children's perspectives on authenticity, moral agency and stimulant drug treatments. Journal of Medical Ethics, 0, 1-8. https://doi.org/10.1136/medethics-2011-100224

Singh, I. (2013a). Brain talk: Power and negotiation in children's discourse about self, brain and behaviour. Sociology of Health \& Illness, 35(6), 813-827. https://doi.org/10.1111/j.1467-9566.2012.01531.x

Singh, I. (2013b). Victimology versus character: New perspectives on the use of stimulant drugs in children. Journal of Medical Ethics, 39(6), 372-373. https://doi.org/10.1136/medethics-2012-101283

Sullivan, A. L., \& Artiles, A. J. (2011). Theorizing racial inequity in special education: Aplying structural inequity theory to disproportionality. Urban Education, 46(6), 1526-1552. https://doi.org/10.1177/0042085911416014

Valencia, R. R. (2010). Dismantling contemporary deficit thinking: Educational thought and practice. New York, NY: Routledge. 
Valera, E. M., Faraone, S. V., Murray, K. E., \& Seidman, L. J. (2007). Meta-analysis of structural imaging findings in Attention-Deficit/Hyperactivity Disorder. Biological Psychiatry, 61, 1361-1369. https://doi.org/10.1016/j.biopsych.2006.06.011

Visser, J., \& Jehan, Z. (2009). ADHD: a scientific fact or a factual opinion? Emotional and Behavioural difficulties, 14(2), 127-140. https://doi.org/10.1080/13632750902921930

Weiler, M. D., Bernstein, J. H., Bellinger, D., \& Waber, D. P. (2002). Information processing deficits in children with Attention/Deficit/Hyperactivity Disorder, Inattentive type, and children with reading disability. Journal of Learning Disabilities, 35(5), 448-461. https://doi.org/10.1177/00222194020350050501

\section{Copyrights}

Copyright for this article is retained by the author(s), with first publication rights granted to the journal.

This is an open-access article distributed under the terms and conditions of the Creative Commons Attribution license (http://creativecommons.org/licenses/by/4.0/). 